\title{
Utilizando PROMETHEE V para seleção de portfólio de projetos de uma empresa de energia elétrica
}

\author{
Hipólito Marcelo Losada López ${ }^{\mathrm{a} *}$, Adiel Teixeira de Almeida ${ }^{\mathrm{b}}$ \\ a*hipolito.losada@yahoo.com.br, UFPE, Brasil \\ balmeidaatd@gmail.com, UFPE, Brasil
}

\begin{abstract}
Resumo
Este trabalho tem por finalidade desenvolver um modelo para a seleção de projetos oriundos do planejamento estratégico de uma empresa do setor elétrico brasileiro, os quais irão compor o portfólio anual. A seleção desses projetos ocorre em um momento em que ainda não existem informações com nível de detalhamento suficiente para a utilização dos critérios quantitativos amplamente empregados como, por exemplo, a taxa interna de retorno e o valor presente líquido. Para o desenvolvimento desse modelo foi utilizado o método de apoio a decisão PROMETHEE V, o qual permitiu a incorporação das restrições existentes ao modelo por meio da utilização de programação linear inteira. 0 modelo desenvolvido mostrou ser extremamente robusto e atendeu aos objetivos estabelecidos.
\end{abstract}

Palavras-chave

Seleção de projetos. Análise de decisão multicritério. PROMETHEE.

\section{Introdução}

O setor elétrico brasileiro (SEB) opera sob concessão, autorização ou permissão do Estado, sendo o serviço público com maior cobertura no território nacional, levando energia elétrica a aproximadamente 99\% da população. 0 seu funcionamento extremamente regulado tem como objetivo fundamental gerir o compromisso de garantia de suprimento e modicidade tarifária no curto, médio e longo prazos (OPERADOR..., 2010).

Inseridas nesse contexto estão 43 empresas de distribuição de energia elétrica que buscam permanentemente o aumento de produtividade conforme padrões internacionais, na tentativa de manter a rentabilidade de seu negócio e, consequentemente, a sobrevivência da organização.

0 aumento de produtividade aliado à manutenção dos indicadores de qualidade são objetivos permanentes no planejamento estratégico dessas organizações, sendo preciso o desenvolvimento de um modelo robusto para a materialização dessa estratégia, por meio da seleção dos projetos que propiciarão o melhor atendimento dos objetivos estratégicos.

Inúmeros são os métodos de apoio multicritério a decisão (AMD) que podem ser aplicados a modelos específicos para solucionar a problemática de seleção do conjunto ótimo de projetos. Entretanto, é necessário que as organizações tenham uma visão sistêmica da gestão de portfólio de projetos, considerando as restrições do ambiente na qual o projeto é desenvolvido, visando que eles não sejam descontinuados do portfólio pela violação de algumas dessas restrições e, consequentemente, acarretando no não cumprimento dos objetivos estratégicos da organização.

\section{Referencial teórico}

\subsection{Base conceitual sobre seleção de portfólio de projetos}

Segundo PMl (PROJECT..., 2006), portfólio é um conjunto de projetos, programas e outras atividades reunido para facilitar o gerenciamento eficaz, visando alcançar os objetivos estratégicos do negócio da organização.

Um ponto importante que deve ser ressaltado é a diferenciação da abordagem da seleção de projetos 
e a seleção de portfólio de projetos. A seleção de projetos tem por objetivo selecionar um conjunto de projetos dentre todos os projetos disponíveis considerando apenas suas características individuais e as restrições impostas pelo sistema. Já a seleção de portfólio de projetos leva em consideração, além das características individuais dos projetos e suas restrições, a sinergia entre eles. No entanto, há vários conceitos diferentes para sinergia na literatura. No que tange à definição de portfólio, sinergia está relacionada à consideração de todos os projetos como um conjunto, desde que seja possível associar a seleção de portfólio de projetos ao problema da mochila em programação linear inteira. No problema da mochila, tem-se como objetivo inserir em uma mochila uma quantidade de itens que otimize o valor dos produtos carregados sem extrapolar o peso estabelecido. 0 conceito sinergia usado no âmbito de seleção de portfólio caracteriza-se quando o valor total agregado pelo portfólio de projetos é maior que a soma dos valores agregados pelos projetos individualmente. 0 estudo de Almeida e Duarte (2011) utiliza um conceito em que a sinergia entre pares de projetos é medida e introduzida no modelo.

0 principal foco do gerenciamento de portfólio é garantir que os projetos e programas sejam analisados, priorizando a alocação dos recursos da organização, garantindo sua consistência e possibilitando que seus projetos estejam alinhados à estratégia da organização (PROJECT..., 2008). Barros, Silva e Mello (2010) destacam que o alinhamento dos projetos permite que os recursos humanos e financeiros sejam dirigidos aos projetos que realmente atendam à estratégia da organização. Segundo pesquisa realizada por Castro e Carvalho (2010), em casos em que uma grande quantidade de projetos que compõem o portfólio é demandada por clientes e fonte importante de receita para a organização, o alinhamento estratégico dos projetos pode tornar-se limitado.

Cooper, Edgett e Kleinschmidt (2000) ressaltam que o gerenciamento de portfólio vai além da mera seleção de projetos e análises de continuar ou abortar projetos. Gerenciamento de portfólio é um processo dinâmico de decisão no qual novos projetos são avaliados, selecionados e priorizados, assim como os projetos existentes podem ser acelerados, extintos ou ter sua prioridade revisada, possibilitando a realocação de recursos.

De acordo com Kerzner (2005), as organizações normalmente estabelecem critérios para a seleção de projetos que podem ser subjetivos, objetivos, quantitativos ou intuitivos e normalmente são baseados em critérios de adequação, dentre os quais ressaltam-se:

- Tecnologia semelhante;
- Canais de distribuição semelhantes;

- Adequação à filosofia ou imagem da empresa;

- Utilização de conhecimentos e técnicas já existentes;

- Adequação à atual estrutura de produção;

- Adequação ao planejamento de longo prazo da organização;

- Adequação às atuais metas de lucro da organização.

Archer e Ghasemzadeh (1999) propõem uma abordagem para a seleção de portfólio de projetos, a qual é dividida em cinco grandes estágios: Pré-seleção; Análise individual dos projetos; Seleção; Seleção do portfólio ótimo; Ajuste do portfólio. Esse processo permite uma análise profunda dos atributos de cada projeto visando a eliminação dos projetos que não alcançam os critérios mínimos preestabelecidos, assim como possibilita selecionar o portfólio ótimo de projetos, no qual os autores sugerem a utilização de métodos multicritério e programação linear inteira de forma a capturar as interações entre diversos projetos, tais como restrições de recursos e interdependências.

Kendall e Rollins (2003) identificaram quatro grandes problemas universais relacionados ao portfólio de projetos: muitos projetos ativos simultaneamente; a existência de projetos que não agregam valor para a organização; projetos não alinhados aos objetivos estratégicos da organização; e portfólio desbalanceado.

Frente ao exposto por Kendall e Rollins (2003), fica clara a necessidade do alinhamento entre a estratégia da organização e o portfólio de projetos selecionados. Nesse sentido, Artto et al. (2008) destacam que a estratégia de um projeto não deve se reter somente ao nível tático e operacional, mas também ao nível institucional e desta forma permitir uma interação significante do projeto com o ambiente no qual ele é empreendido.

No que tange ao sucesso do portfólio de projetos, Meskendahl (2010) faz a proposição de que ele consiste basicamente na média simples do sucesso dos projetos que o compõem, no balanceamento dos projetos, na sua adequação estratégica, bem como na utilização de sinergias, e está positivamente relacionado com o sucesso do negócio, que consiste no sucesso econômico e na preparação para o futuro. Segundo o mesmo autor, a estruturação do portfólio de projetos, isto é, sua consistência, integração, formalização e acompanhamento, está relacionada positivamente com o seu sucesso.

\subsection{A tomada de decisão multicritério}

0 AMD busca realizar o estabelecimento de relações de preferências (subjetivas) perante várias alternativas avaliadas sob a influência de vários critérios durante o processo decisório (ALMEIDA; COSTA, 2003). 
Para Gomes e Gomes (2012), a abordagem multicritério tem como características:

- Vários atores envolvidos, definindo os aspectos relevantes do processo de decisão, caracterizando um processo decisório complexo;

- Cada ator tem seu próprio juízo de valores;

- Reconhecer os limites de objetividade, levando em conta a subjetividade dos atores;

- Parte do princípio de que o problema não é bem estruturado nem claramente definido.

Roy (1996) enfatiza que apoio à decisão está apenas de longe relacionado à busca pela verdade, sendo uma maneira de guiar ações em ambientes complexos, especialmente onde há conflitos entre pontos de vista.

0 grande mérito do AMD é possibilitar a aceitação da subjetividade como parte do processo decisório, apoiando o decisor por meio de algoritmos $\mathrm{e}$ metodologias a explicitar suas preferências de forma confortável, obtendo os melhores resultados (GOMES; GOMES, 2012).

\subsection{Métodos multicritério na seleção de portfólio de projetos}

Grande parte das decisões de investimentos passa pelo enfoque da decisão multicritério, sendo que a seleção do método abrange a análise do contexto no qual o problema está inserido, dos stakeholders e das estruturas de preferência associadas ao problema (ALMEIDA; COSTA, 2003).

Vários autores abordam o estado da arte na aplicação de métodos de apoio multicritério à decisão (AMD) para a priorização e seleção de projetos em diversas empresas e mercados. Esse tópico abordará, utilizando nove aplicações práticas pesquisadas junto ao meio acadêmico, os principais direcionadores para a escolha dos métodos de apoio multicritério à decisão (AMD) em vários ramos do mercado.

Smith-Perera et al. (2010) destacam o sucesso na aplicação do método ANP (Analytic Network Process) na seleção do portfólio de projetos na empresa EDC (La Electricidad de Caracas), da Venezuela. Nesse estudo de caso, a escolha pelo ANP se deveu por este levar em consideração a interdependência entre os critérios, evitando em grande parte o problema da compensação, pois algumas técnicas de MCDA funcionam bem sob o pressuposto da independência dos critérios, a qual nem sempre é realista no campo estratégico de seleção de portfólio, onde múltiplas dimensões de informações relacionadas devem ser consideradas na análise, podendo levar a avaliações não otimizadas.

Aragonés-Beltrán, Chaparro-González e RodriguézPozo (2010) abordam em seu trabalho para seleção de projetos de investimento em plantas de energia solar fotovoltaica a utilização do método ANP. A grande novidade da abordagem neste trabalho está em considerar no processo de tomada de decisão o ponto de vista dos riscos do projeto e levar em consideração as influências dos riscos, usando o método ANP.

Outra aplicação de método multicritério no campo da geração de energia é demonstrada em Haurant, Oberti e MUSELLl (2011), que utilizam o ELECTRE IS para a seleção de plantas de energia solar fotovoltaica na França. Segundo os autores, o uso do método ELECTRE IS se deu devido ao tipo de problemática encontrada, por levar em conta o conhecimento imperfeito utilizando limiares de preferência e indiferença e por ser um método mais refinado cientificamente para a problemática de escolha, incluindo uma rigorosa análise de robustez dos resultados.

Mavrotas, Diakoulaki e Capros (2003) utilizam o método ELECTRE TRI associado à programação linear inteira para a seleção de projetos de geração de energia eólica. Os autores destacam que a principal vantagem desse método é poder lidar com um grande número de alternativas, as quais não são possíveis de e/ou não precisam ser ranqueadas em uma pré-ordem estrita. Outro ponto destacado é que o método é flexível o bastante para descrever adequadamente o modelo de preferências do tomador de decisão.

Em outro exemplo de aplicação de métodos multicritério para a seleção do portfólio de projetos, Buchanan e Sheppard (1998) destacam a aplicação do método ELECTRE 111 para selecionar e ordenar projetos na Electricity Corporation of New Zealand (ECNZ), uma empresa do setor elétrico da Nova Zelândia. Segundo os autores, a escolha do método recaiu sobre o ELECTRE 111, em detrimento dos métodos AHP e SMART, pois o mesmo incorpora a natureza difusa da tomada de decisão por meio da utilização dos limiares de preferência e indiferença e por causa da enorme quantidade de comparações aos pares que são requeridas pelo AHP.

No setor de P\&D, Meade e Presley (2002) descrevem um estudo de caso realizado em uma pequena empresa de alta tecnologia nos Estados Unidos. Foi destacado que uma vantagem do ANP é a possibilidade de fácil adaptação de um modelo básico, para uma situação particular, podendo ser facilmente adicionados critérios de decisão que uma empresa considere cruciais no processo decisório.

Ampliando a utilização de métodos multicritério em projetos de PED, tem-se o trabalho realizado por Greiner et al. (2003), no qual é aplicada uma abordagem híbrida, utilizando AHP e programação inteira para a seleção de projetos de desenvolvimento de sistemas de armamento. 0 processo decisório 
suportado por esse método levou a melhorias substanciais na seleção de projetos de desenvolvimento de armamentos no Departamento de Defesa dos Estados Unidos, provendo uma avaliação sistemática de critérios intangiveis e qualitativos.

Cheng e Li (2005) decidiram desenvolver um modelo próprio para o setor da construção civil. Nesse trabalho, foi sugerida a realização de um estudo de viabilidade detalhado nos projetos selecionados pelo modelo proposto, ressaltando-se que o ANP pode atuar conjuntamente com estudos de viabilidade, proporcionando uma solução com melhores resultados para a organização.

Para a seleção de projetos de sistema de informação, Lee e Kim (2001) desenvolveram um modelo utilizando o método ANP, técnica de Delphi e programação linear inteira. Nesse modelo, os autores utilizam a técnica de Delphi para a definição dos objetivos, critérios e relacionamento de interdependência entre os critérios e para a determinação das consequências dos projetos ante os critérios selecionados.

Na Tabela 1 é apresentado um resumo dos modelos estudados.

Frente ao cenário apresentado, este trabalho tem como finalidade elaborar um modelo estruturado para a seleção de projetos que irão compor o portfólio de projetos estratégicos de um grupo do setor elétrico brasileiro, utilizando um método de apoio multicritério à decisão (AMD).

\section{Descrição do problema e de seu contexto}

\subsection{Descrição do contexto do problema}

0 problema a ser descrito se passa em um tradicional grupo atuante no setor elétrico brasileiro, grupo esse integrado por cinco distribuidoras de energia elétrica, duas empresas de serviços, sendo uma prestadora de serviços para o setor elétrico e uma comercializadora de energia elétrica. 0 grupo também possui uma empresa com atuação na geração de energia elétrica.

As empresas de distribuição de energia elétrica do grupo estão inseridas em um mercado caracterizado por um monopólio atendido por uma concessão pública que possui regulamentação excessivamente rígida (SCHETTINO; CORDEIRO, 2009).

0 setor elétrico tem sido beneficiado pelo forte crescimento de demanda. Fatores como programas de transferência de renda, forte estímulo ao setor exportador e crescimento do consumo das famílias têm permitido taxas de crescimento da demanda acima do PIB por diversos meses.

As empresas do setor começam a ter seus resultados afetados pelas revisões tarifárias recentes, com forte contração das margens, parcialmente compensada pelo crescimento da demanda.

Esse cenário direciona o grupo a adotar como principal objetivo estratégico das empresas de distribuição a excelência operacional, isto é, operar suportando o crescimento de mercado e atendendo as metas de qualidade estabelecidas pelo órgão regulador, otimizando os recursos disponíveis e possibilitando assim uma maior rentabilidade.

Por sua vez, as empresas de serviços estão inseridas em um mercado extremamente competitivo, no qual fatores como inovação, flexibilidade, custo e credibilidade são importantíssimos e direcionam as estratégias adotadas por essas empresas para ampliação de mercado.

Desde 2001, as empresas do grupo vêm se beneficiando de um processo estruturado de planejamento estratégico na condução dos seus negócios, o qual está fortemente enraizado na cultura da organização. Esse processo de planejamento estratégico é realizado em um ciclo de três anos, sendo revisado anualmente para o realinhamento de sua estratégia ao comportamento do setor.

0 planejamento estratégico realizado pelas empresas utiliza o Balanced Scorecard (BSC) como uma de suas principais ferramentas, a qual possibilita a geração de metas alinhadas com a missão do

Tabela 1. Métodos utilizados.

\begin{tabular}{lcc}
\multicolumn{1}{c}{ Referência } & Método & Seleção de projetos ou portfólio? \\
\hline Smith-Perera et al. (2010) & ANP & Portfólio \\
$\begin{array}{l}\text { Aragonés-Beltrán, Chaparro-González e Rodriguéz- } \\
\text { Pozo (2010) }\end{array}$ & ANP & Projeto \\
Haurant, Oberti e Muselli (2011) & ELECTRE 1S & Projeto \\
Mavrotas, Diakoulaki e Capros(2003) & ELECTRE TRl & Projeto \\
Buchanan e Sheppard (1998) & ELECTRE 111 & Projeto \\
Meade e Presley (2002) & ANP & Projeto \\
Greiner et al. (2003) & AHP & Portfólio \\
Cheng e li (2005) & ANP & Projeto \\
Lee e Kim (2001) & ANP & PCtorgia \\
\hline
\end{tabular}

Fonte: autor. 
grupo. No processo de formulação da estratégia, cada unidade de negócio (empresas do grupo) ou unidade de apoio (áreas corporativas que atendem a todas as empresas do grupo) possui seu próprio mapa estratégico, conforme mostrado na Figura 1. No caso das empresas de distribuição de energia elétrica, o mapa estratégico inicialmente é subdividido em temas: comercial, operacional e segurança e meio ambiente, cada qual com seus respectivos subtemas, visando facilitar o desdobramento das iniciativas.

0 desdobramento resulta em BSCs específicos para cada empresa do grupo e, por consequência, em iniciativas que, se selecionadas, se transformarão nos projetos estratégicos que irão compor o portfólio do grupo. Os BSCs sofrem ajustes quando uma determinada iniciativa não é selecionada.

Esse processo como um todo vem garantindo um aprimoramento significativo do desempenho de cada uma das empresas do grupo.

\subsection{Descrição do problema}

Os projetos que compõem o portfólio das empresas do grupo têm, basicamente, pelo menos uma das seguintes origens:

- Projetos demandados pelo planejamento elétrico e órgão regulador;

- Demandas de Tl;

- Projetos de P\&D;

- Projetos do planejamento estratégico;

- Contratos com clientes.
Os projetos oriundos do planejamento elétrico, demandas de Tl e P\&D têm um processo de seleção bem estruturado, que otimiza os recursos a serem investidos. Por sua vez os projetos oriundos de contratos com clientes são empreendidos conforme demandados.

0 problema em questão é que em cada revisão anual da estratégia, o grupo desdobra seu planejamento estratégico em aproximadamente 80 novos projetos que, devido à grande quantidade, necessitam passar por um processo de seleção, o qual tem a finalidade de definir os que realmente são relevantes e têm potencial de agregar valor aos negócios do grupo.

0 grande desafio enfrentado está centrado justamente nesse processo de seleção, já que existem muitas incertezas quando da realização do mesmo.

A seleção se dá no momento em que os projetos ainda não têm um nível de planejamento mínimo, isto é, ainda não estão detalhados com, por exemplo, as quantidades e perfis dos recursos humanos necessários, estimativas de custos, prazo de implantação, riscos envolvidos, entre outros, acarretando um grande desconforto para o processo decisório.

Por sua vez, não é possível realizar o planejamento detalhado dos projetos antes do processo de seleção, pois além de não haver tempo suficiente para isso, grande parte do esforço seria desperdiçado, já que aproximadamente $60 \%$ dos projetos não são selecionados para compor o portfólio do ano.

Frente ao cenário exposto, este trabalho visa desenvolver um modelo de seleção de projetos que permita ao grupo escolher o melhor portfólio de projetos de forma a conseguir materializar a estratégia

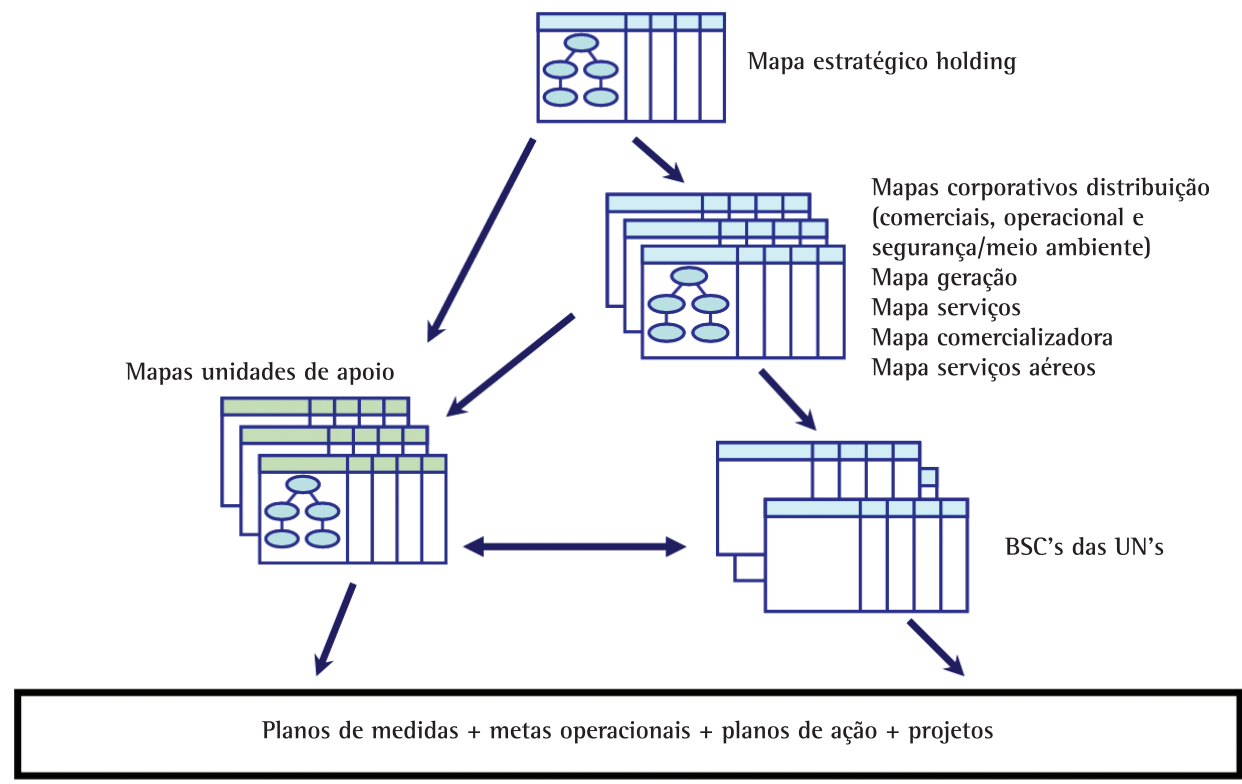

Figura 1. Desdobramento da estratégia do grupo. Fonte: empresa de energia. 
formulada em seu ciclo de planejamento estratégico, otimizando os recursos disponíveis e possibilitando um crescimento sustentável.

\section{Construção do modelo}

Dentre os problemas anteriormente descritos de seleção de projetos, esse modelo se destina a tratar especificamente da seleção de projetos que são desdobrados pelo planejamento estratégico, para tanto se torna necessário estabelecer um processo a ser seguido anualmente.

\subsection{Descrição do modelo geral para seleção de projetos}

Como visto anteriormente, existe uma enorme quantidade de métodos multicritério de apoio à decisão. Esses métodos possuem características distintas, sendo necessário que o analista de decisão formule um processo para que seja selecionado o modelo ideal para a problemática em questão e, consequentemente, escolhido um método multicritério adequado.

Segundo Almeida (2011), o processo de definição do modelo a ser utilizado depende de uma série de hipóteses ou formas distintas de estabelecer as variáveis do problema, tais como: espaço de alternativas, escolha dos critérios etc.
0 processo de definição do modelo pode ser associado à figura de um funil, com uma gama de modelos possíveis em sua entrada- em função de cada pressuposto adotado, alguns modelos são eliminados. Na saída do funil "sobra" o modelo selecionado para a solução da problemática.

Almeida (2011) sugere que a construção do modelo passe por uma série de etapas, como descritas na Figura 2, sendo que não há a necessidade de uma sequência rígida e que o processo pode passar por refinamentos sucessivos, os quais muitas vezes podem levar a uma nova passagem, em etapas anteriores.

Deve-se destacar que as etapas de definição da racionalidade, avaliação intracritério e intercritério são desenvolvidos de forma integrada para a definição do método multicritério.

Culminando ao final do processo, na implementação da ação ou conjunto de ações sugeridas pelo modelo. A visão antecipada desse fator por parte do decisor pode exercer uma forte influência nas etapas anteriores, podendo inclusive afetar na aceitação dos procedimentos adotados (ALMEIDA, 2011).

Algumas características e pressupostos devem ser definidos durante o processo de definição de um modelo geral para a seleção de projetos. Muitas dessas definições serão questões de cunho ambiental que necessitam serem analisadas antes da adoção do modelo e avaliadas anualmente, sempre antes que um novo ciclo inicie.

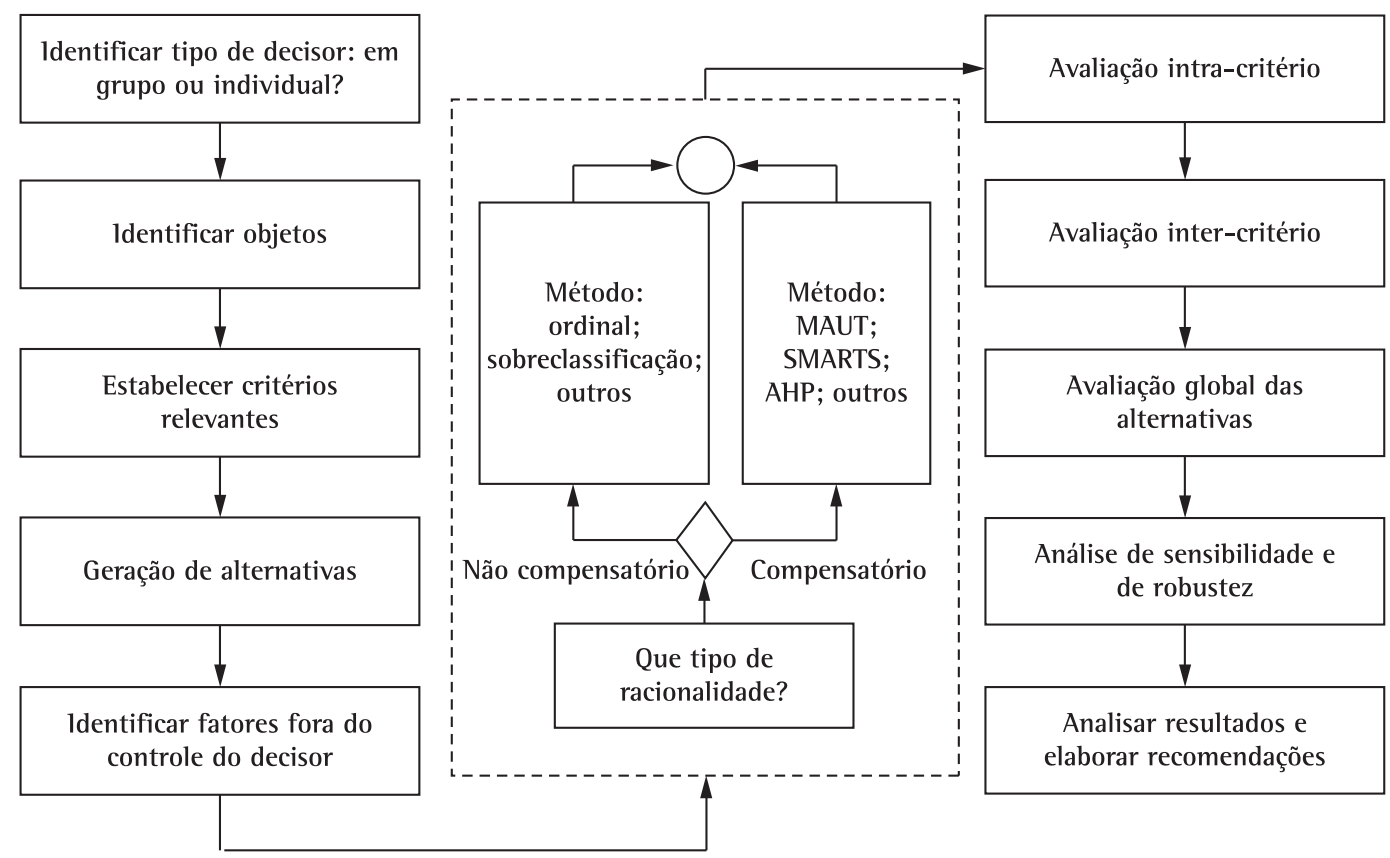

Figura 2. Etapas do processo de modelagem. Fonte: adaptado de Almeida (2011). 
Como exemplo para essa questão, observa-se que neste estudo foi considerada uma racionalidade não compensatória (ver Figura 2). Nesse caso não se pode adotar uma abordagem baseada nos métodos clássicos de otimização combinatória multiobjetivo, visto que estão relacionados a uma racionalidade compensatória, diferentemente da opção adotada neste estudo, onde se observa uma racionalidade não compensatória, com o uso, portanto, de um método de sobreclassificação que atende a condição de ser não compensatório.

Outro fator a ser analisado é a questão das restrições impostas ao modelo. Não existe organização sem algum tipo de limitação de recursos, sejam eles humanos, financeiros ou de equipamentos. Esse fator leva a inserir no modelo as restrições pertinentes, o que permitirá a implantação do portfólio dentro das limitações impostas pelo ambiente no qual a organização está envolvida.

Definir se o problema é multiobjetivo, isto é, se existe mais de uma alternativa a ser avaliada por múltiplos objetivos, sendo esses objetivos muitas vezes conflitantes entre si, também é importante para a elaboração do modelo. Quando o problema é multiobjetivo, pode ser adotado, para a construção do modelo, um método multicritério de apoio à decisão (MCDA).

Para o desenvolvimento do modelo, o analista deve avaliar anualmente se o processo de seleção de projetos será uma decisão individual ou em grupo. Esse fator terá grande influência na escolha do método a ser adotado e no processo decisório como um todo.

Assim como o tipo de decisão a ser adotada, deve ser avaliado se os critérios estabelecidos continuam válidos ou se existe um novo fator a ser considerado na avaliação dos projetos. Vale a pena salientar que os critérios a serem utilizados devem ser relevantes para o processo.

Na definição do modelo, torna-se necessário que o analista verifique anualmente se a construção do modelo irá seguir uma abordagem de seleção de portfólio ou seleção de projetos, visto que existem premissas específicas a serem adotadas, tal como a forma com que será analisada a sinergia entre projetos.

Finalmente deve-se analisar se a escolha do método de agregação multicritério a ser adotado pelo analista continua válida para o ciclo em questão.

\subsection{Modelo de decisão para seleção de projetos}

Com base no modelo do item anterior é apresentada a seguir uma aplicação, que embora não seja real pode ser considerada realística, visto que é desenvolvida com base em dados e situações reais obtidos dentro da empresa onde esse estudo foi desenvolvido.
Visando o balanceamento do portfólio, esse modelo prevê que todos os projetos propostos no ciclo anual devam ser classificados em quatro categorias: Projetos para ampliar margem; Projetos para reduzir riscos regulatórios; Projetos para aumentar a satisfação do cliente e Projetos para promover negócios competitivos. Essa medida visa possibilitar uma concorrência justa entre projetos, evitando com isso que determinados projetos de uma categoria sejam sempre preteridos.

Apesar da categorização dos projetos, o modelo aplica o método PROMETHEE 11 em todo o conjunto de projetos em uma única vez, pois caso contrário poderia haver a inversão de ordem em situações de inclusão de novas alternativas, em função de uma possível recategorização de algum projeto.

A seguir serão descritas as diretrizes que nortearam a construção do modelo em questão.

a) 0 processo envolve decisão individual ou em grupo:

Após o desenvolvimento dos mapas estratégicos por cada UN (unidade de negócios) e UA (unidade de apoio), são descritas as ações (projetos) que deverão ser implantadas para possibilitar o alcance dos objetivos estabelecidos pela estratégia do grupo.

Para avaliação dos projetos pelo decisor, eles possuem um descritivo que sintetiza o seu objetivo, principais entregas tangíveis, prazo esperado, assim como uma quantidade estimada de recursos humanos (homem-hora - HH).

No modelo desenvolvido, o responsável pelo julgamento dos projetos para cada critério estabelecido é um membro da alta direção do grupo, caracterizando assim, um processo de decisão individual.

b) Escolha entre a abordagem de seleção de projetos ou portfólio:

No modelo em questão, será assumida a utilização da abordagem de seleção de projetos em virtude da impossibilidade de definir as sinergias entre os projetos, em um momento muito precoce do planejamento, assim como pela imprecisão embutida no julgamento dos critérios estabelecidos.

\section{c) Descrição dos critérios relevantes:}

Após a análise do contexto e do problema, foram estabelecidos os critérios para julgamento dos projetos, assim como os respectivos pesos.

Para elencar os critérios mais importantes para o processo decisório, foram entrevistados especialistas e o decisor, visando a obtenção de critérios capazes de representar os objetivos da organização naquele momento, assim como "mantê-los" passíveis de avaliação. Os seguintes critérios foram considerados relevantes para a problemática em questão: Impacto no resultado, Alinhamento estratégico, Melhoria dos indicadores regulados, Contribuição para satisfação 
dos clientes, Probabilidade de alcançar os benefícios e Complexidade.

0 julgamento da importância relativa dos critérios, isto é, informação intercritérios, foi realizado por meio de uma entrevista com o decisor, na qual foi definido o grau de importância para cada critério. 0 critério mais importante, na visão do decisor, foi Impacto no resultado, e o de menor importância foi Complexidade. Os critérios, com a respectiva importância, foram:

- Impacto no resultado - 100;

- Alinhamento estratégico - 80;

- Melhoria dos indicadores regulados - 60;

- Contribuição para satisfação dos clientes - 50;

- Probabilidade de alcançar os benefícios - 40;

- Complexidade - 20.

Para o processo de normalização foi utilizado o procedimento três descrito por Almeida (2011):

$$
v_{j}^{\prime}\left(a_{i}\right)=v_{j}\left(a_{i}\right) /\left[\sum_{i} v_{j}\left(a_{i}\right)\right]
$$

Esse procedimento aplica a divisão de cada grau de importância pela soma total, podendo ele ser interpretado como um percentual da soma total, sendo os valores normalizados obtidos no intervalo: $0 \leq \mathrm{v}_{\mathrm{j}}^{\prime}\left(\mathrm{a}_{\mathrm{i}}\right) \leq 1$.

Para a avaliação de cada projeto perante os critérios estabelecidos, foi dimensionada uma escala verbal para utilização do decisor. Esse procedimento permitiu facilidade no momento do julgamento dos projetos. Para a criação de uma característica quantitativa, posteriormente foi realizada a conversão da escala verbal em escala numérica ordinal.

Na Tabela 2 é apresentado o resumo dos critérios utilizados, os pesos já normalizados, assim como a escala verbal utilizada e sua correspondente escala numérica.

\section{d) Restrições do modelo:}

0 ambiente no qual os projetos são empreendidos é cercado por diversos tipos de restrições. Podem-se citar, por exemplo, restrições financeiras, restrições de prazo, restrições de recursos humanos, entre outras.

Nesse modelo tratar-se-ão especificamente das restrições de recursos humanos. 0 principal motivo para essa decisão foi a pouca disponibilidade de especialistas para atuarem em projetos, sendo necessário que eles se dividissem entre os projetos e as atividades do dia a dia da organização. Uma demanda excessiva de recursos especializados em projetos poderia comprometer as atividades operacionais da organização. Em função dessa especificidade, o grupo definirá anualmente a quantidade de homens-horas disponíveis para a implantação dos projetos oriundos do desdobramento do planejamento estratégico. A quantidade de homenshoras disponivel para cada categoria será proporcional à sua quantidade de projetos em relação ao total de projetos propostos por todas as categorias.

Sendo HHD a quantidade disponibilizada para a implantação dos projetos e Qi a quantidade de projetos de uma categoria i, tem-se:

$$
H H i=\frac{Q i}{\sum_{i=1}^{m} Q i} \times H H D
$$

\begin{tabular}{|c|c|c|c|c|c|}
\hline Critério & Descrição & Peso & Escala verbal & Escala numérica & Sentido \\
\hline \multirow{3}{*}{ Complexidade } & \multirow{3}{*}{ Complexidade de execução do projeto } & \multirow{3}{*}{0,0571} & Baixo & 1 & \multirow{3}{*}{ Menor Melhor } \\
\hline & & & Médio & 2 & \\
\hline & & & Alto & 3 & \\
\hline \multirow{3}{*}{ Impacto no resultado } & \multirow{3}{*}{ Resultado financeiro que o projeto trará para o grupo } & \multirow{3}{*}{0,2857} & Baixo & 1 & \multirow{3}{*}{ Maior Melhor } \\
\hline & & & Médio & 2 & \\
\hline & & & Alto & 3 & \\
\hline \multirow{3}{*}{$\begin{array}{l}\text { Alinhamento } \\
\text { estratégico }\end{array}$} & \multirow{3}{*}{$\begin{array}{l}\text { Grau de alinhamento do projeto com as estratégias } \\
\text { do grupo }\end{array}$} & \multirow{3}{*}{0,2286} & Baixo & 1 & \multirow{3}{*}{ Maior Melhor } \\
\hline & & & Médio & 2 & \\
\hline & & & Alto & 3 & \\
\hline \multirow{3}{*}{$\begin{array}{l}\text { Probabilidade de } \\
\text { alcançar os benefícios }\end{array}$} & \multirow{3}{*}{$\begin{array}{l}\text { Define a probabilidade de o projeto alcançar os } \\
\text { objetivos }\end{array}$} & \multirow{3}{*}{0,1143} & Baixo & $35 \%$ & \multirow{3}{*}{ Maior Melhor } \\
\hline & & & Médio & $60 \%$ & \\
\hline & & & Alto & $85 \%$ & \\
\hline \multirow{3}{*}{$\begin{array}{l}\text { Contribuição para } \\
\text { satisfação dos clientes }\end{array}$} & \multirow{3}{*}{$\begin{array}{l}\text { Contribuição do objetivo do projeto para a satisfação } \\
\text { dos clientes do grupo }\end{array}$} & \multirow{3}{*}{0,1429} & Baixo & 1 & \multirow{3}{*}{ Maior Melhor } \\
\hline & & & Médio & 2 & \\
\hline & & & Alto & 3 & \\
\hline \multirow{3}{*}{$\begin{array}{l}\text { Melhoria dos } \\
\text { indicadores regulados }\end{array}$} & \multirow{3}{*}{$\begin{array}{l}\text { Grau de melhoria que o projeto propiciará aos } \\
\text { indicadores regulados pela ANEEL }\end{array}$} & \multirow{3}{*}{0,1714} & Baixo & 1 & \multirow{3}{*}{ Maior Melhor } \\
\hline & & & Médio & 2 & \\
\hline & & & Alto & 3 & \\
\hline
\end{tabular}

Tabela 2. Critérios do modelo proposto. 
Dessa forma pode ser descrito que para compor as restrições tem-se o vetor $\mathrm{HH}$ de disponibilidade de homens-horas para cada categoria:

$$
H H=\left[H H_{1}+H H_{2}+\ldots H H m\right]
$$

Logo, o conjunto de restrições será:

$$
H H \leq H H D
$$

Projetos mandatórios: em algumas situações torna-se necessária a inclusão de um projeto demandado pelo órgão regulador ou poder competente. Nesse caso deve ser forçada a realização do projeto no modelo estabelecido.

Sendo $C_{M}$ o conjunto de projetos mandatórios a constarem na seleção de projetos. Obtém-se o conjunto de restrições como:

$$
x_{i}=1, \forall X_{i} \in C_{M}
$$

Cabe salientar que os projetos que atendam a essa restrição devem ser identificados antes da implementação do modelo, sendo os mesmos retirados da lista de projetos candidatos ao portfólio, assim como o respectivo quantitativo de $\mathrm{HH}$.

Projetos mutuamente excludentes: quando um e somente um projeto entre um conjunto de projetos pode ser selecionado para compor o portfólio de projetos.

Nesse caso a restrição é caracterizada por:

$$
\sum_{X_{i} \in C_{M E}} x_{i} \leq 1
$$

sendo $\mathrm{C}_{\mathrm{ME}}$ o conjunto de projetos mutuamente excludentes.

Projetos dependentes: quando, para a implantação de um projeto, é necessário que outro projeto seja implantado. Nesse caso, para o primeiro projeto ser selecionado, obrigatoriamente terá que ser selecionado o segundo projeto.

Sendo assim, essa restrição pode ser apresentada como:

$$
x_{j}-x_{i} \leq 0
$$

onde $x_{j}$ depende da implantação de $x_{i}$.

e) Escolha do método de agregação multicritério

0 método de agregação multicritério escolhido para a resolução do modelo foi o PROMETHEE V. A seguir são destacados os fatores relevantes para a escolha deste método:
- 0 método possibilita uma pré-ordem completa, utilizando um fluxo de superação líquido $\left(\emptyset_{\mathrm{i}}\right)$ entre alternativas;

- Possibilidade de escolher um subconjunto de alternativas possíveis, atendendo as restrições de quantidade de projetos, dependência de projetos e recursos, utilizando programação linear inteira binária;

- Facilidade no entendimento do método por parte do decisor, assim como facilidade da construção do modelo pelo analista de decisão; e

- Os pesos estabelecidos representam a importância atribuída pelo decisor aos critérios do modelo, não sendo necessária a aplicação de procedimentos de trade-off para a definição dos pesos. Isso torna 0 entendimento do processo de atribuição de peso mais simples para o decisor.

0 método PROMETHEE $V$ é a combinação do método PROMETHEE 11 otimizado com a utilização da programação linear inteira para a problemática de portfólio (BRANS; MARESCHAL, 1992; ALMEIDA, 2011; GOMES; ARAYA; CARIGNAN, 2004). Uma abordagem mais ampla da aplicação do método PROMETHEE $\checkmark$ na seleção de portfólios pode ser encontrada em Vetschera e Almeida (2012). A forma de evitar a questão do fluxo líquido negativo é proposta por Mavrotas, Diakoulaki e Caloghirou (2006), a qual, no entanto, também foi questionada por Almeida e Vetschera (2012).

0 fluxo de sobreclassificação líquido é dado por meio da seguinte formulação:

$\phi(\mathrm{a})=\phi_{+}(\mathrm{a})-\phi_{-}(\mathrm{a})$

Sendo,

Fluxo de sobreclassificação de saída da alternativa a:

$\phi_{+}(a)=\frac{1}{n-1} \sum_{b \in A} \pi(a, b)$

Fluxo de sobreclassificação de entrada da alternativa a:

$\phi_{-}(a)=\frac{1}{n-1} \sum_{b \in A} \pi(b, a)$

Após a aplicação do método PROMETHEE 11 para a geração da ordenação das alternativas, é aplicada a otimização utilizando programação linear inteira binária descrita a seguir (BRANS; MARESCHAL, 1992; ALMEIDA, 2011):

$\max \cdot \sum_{i} \phi_{i} x_{i}$

Sujeito a: 
$\sum_{r} \delta_{r i} x_{i}\left[\begin{array}{l}\geq \\ \leq \\ =\end{array}\right] \varphi_{r}$

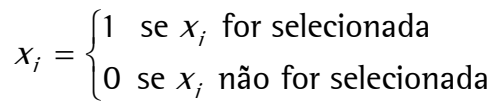

Sendo:

- $\emptyset_{\mathrm{i}}$ é o fluxo líquido da alternativa $\mathrm{x}_{\mathrm{i}}$;

- $\varphi_{\mathrm{r}}$ é o valor referente à restrição $\mathrm{r}$;

- $\delta_{r i}$ é a contribuição da alternativa $x_{i}$ relativa à restrição $r$.

0 programa matemático subjacente ao PROMETHEE $\checkmark$ foi apresentado acima e está bem esclarecido na literatura, conforme referências apresentadas (BRANS; MARESCHAL, 1992; ALMEIDA, 2011; GOMES; ARAYA; CARIGNAN, 2004; VETSCHERA; ALMEIDA, 2012; MAVROTAS; DIAKOULAKI; CALOGHIROU, 2006; ALMEIDA; VETSCHERA, 2012). Destaca-se que o foco deste artigo foi estabelecido na modelagem de um problema de portfólio de projetos em uma empresa de energia elétrica.

\subsection{Aplicação do modelo}

$\mathrm{Na}$ definição do modelo para seleção dos projetos estratégicos que irão compor o portfólio do grupo foram coletados 83 projetos elencados durante 0 ciclo de planejamento estratégico do ano de 2010 para participarem do processo de seleção. Visando facilitar o julgamento do decisor, para cada projeto proposto o departamento responsável preencheu a ficha de proposição de projeto, a qual continha as informações básicas do projeto, tais como: escopo sumário, prazo e custo macro e a contribuição para a estratégia da organização. Na aplicação do modelo, a função escolhida para o método foi a Verdadeiro critério, em função da própria característica da avaliação das alternativas, visto que não há dúvidas, por parte do decisor, no estabelecimento de situação de indiferença ou preferência para os critérios.

Uma das restrições estabelecidas pelo decisor foi da ordem de recursos humanos, isto é, o decisor definiu que para o ciclo 2010 os projetos estratégicos poderiam consumir 20 mil homens-horas. Aplicando a Equação 07, as categorias a seguir ficaram com as seguintes restrições de homem-hora:

- Categoria ampliar margem: $4.096 \mathrm{HH}$;

- Categoria risco regulatório: $5.542 \mathrm{HH}$;

- Categoria satisfação do cliente: $3.374 \mathrm{HH}$;

- Categoria negócios competitivos: $6.988 \mathrm{HH}$.
Um conjunto de projetos têm restrições de dependência, são eles:

- 0 projeto NC04 depende da implantação do projeto NC05;

- 0 projeto NC06 depende da implantação do projeto $\mathrm{NCO}$;

- 0 projeto SC07 depende da implantação do projeto SC06;

- 0 projeto SC10 depende da implantação do projeto SC11.

Em virtude da quantidade limitada de recursos capacitados para realizar o gerenciamento de projetos, o decisor impôs que a quantidade máxima de projetos de cada categoria não poderia extrapolar a metade dos projetos propostos da mesma categoria.

Cabe salientar que no conjunto de projetos levantados não existiam projetos mandatórios, tampouco projetos mutuamente excludentes.

Com isso tem-se a função objetivo e as restrições do modelo definidas como:

$\max \cdot \sum_{i} \phi_{i} x_{i}$

Sujeito a:

$\Sigma H H_{A M} \leq 4096$

$\Sigma H H_{R R} \leq 5542$

$\Sigma H H_{S C} \leq 3374$

$\Sigma H H_{N C} \leq 6988$

$\Sigma Q p_{A M} \leq 8$

$\Sigma Q p_{R R} \leq 11$

$\Sigma Q p_{S C} \leq 7$

$\Sigma Q p_{N C} \leq 14$

$S C 07-S C O 6 \leq 0$

$S C 10-S C 11 \leq 0$

NCO4 - NVO5 $\leq 0$

NCO6 - NCO2 $\leq 0$

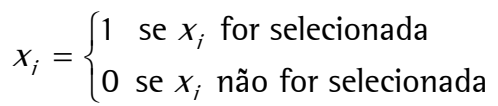

Sendo que:

- $\emptyset_{\mathrm{i}}$ é o fluxo líquido de superação da alternativa $\mathrm{x}_{\mathrm{i}}$;

- $\Sigma Q p$ é o somatório da quantidade de projetos de uma determinada categoria;

- $\Sigma H H$ é o somatório de homens-horas dos projetos de uma determinada categoria.

\section{a) Apresentação dos dados}

Para o processamento do modelo foi utilizado o add-in para Excel SANNA2009, elaborado por Jablonský (2010) para os cálculos do PROMETHEE 11 e, após a aplicação da otimização, utilizado o Solver do Excel. 
Tabela 3. Análise de sensibilidade.

\begin{tabular}{llcc}
\hline \multicolumn{1}{c}{ Critério } & \multicolumn{2}{c}{ Pesos } & \\
\hline Impacto no resultado & Original & Análise de sensibilidade 1 & Análise de sensibilidade 2 \\
Alinhamento estratégico & 0,2857 & 0,3143 & 0,2714 \\
Melhoria de indicadores regulados & 0,2286 & 0,2194 & 0,2331 \\
Contribuição para satisfação dos clientes & 0,1714 & 0,1646 & 0,1749 \\
Probabilidade de sucesso & 0,1429 & 0,1371 & 0,11657 \\
Complexidade & 0,1143 & 0,1097 & 0,0583 \\
Soma & 0,0571 & 1,0549 & 1,0000 \\
\hline
\end{tabular}

Para a categoria Ampliar margem, 7 projetos foram selecionados, sendo que nem a restrição da quantidade máxima de projetos nem a restrição de quantidade de homens-horas máxima limitaram a otimização do problema, pois apenas os projetos com fluxo líquido positivo foram selecionados, possibilitando com isso o fluxo máximo.

$\mathrm{Na}$ categoria Risco regulatório foram selecionados 11 projetos, todos com fluxo líquido positivo, sendo que a restrição da quantidade máxima de projetos atuou, já que quatro projetos de fluxo líquido positivo não figuraram entre os projetos selecionados.

Na categoria Satisfação do cliente, 4 projetos foram selecionados, sendo que nenhum projeto com restrições de dependência foi selecionado. Nenhum dos projetos descartados do portfólio apresenta fluxo líquido positivo.

Para a categoria Negócios competitivos a restrição de quantidade máxima de projetos atuou e 14 projetos com fluxo líquido positivo foram selecionados, sendo que 5 projetos com fluxo líquido positivo não puderam ser selecionados. Outro ponto de destaque foi que dos projetos que possuíam uma restrição de dependência, apenas o NC05 foi selecionado, já que o mesmo não apresentava restrições à sua implantação. Com isso, a implantação do projeto NC04 necessitará passar por um novo processo de seleção no ciclo de planejamento estratégico do próximo ano.

De maneira consolidada, foram selecionados um total de 36 projetos que consumiram 15.240 homenshoras. Cabe ressaltar que em nenhum momento a restrição de homens-horas atuou como restrição do problema, mas sim a limitação imposta pelo decisor de quantidade de projetos. Dos 47 projetos excluídos do portfólio, nove apresentaram fluxo líquido positivo, isso indica que caso o decisor flexibilizasse a restrição de quantidade de projetos para compor o portfólio, o valor gerado pelo portfólio poderia ser acrescido em $6,5 \%$.

\section{b) Análise de sensibilidade}

Após a análise preliminar dos dados, foram realizadas duas análises de sensibilidade. Para a primeira análise foi aumentado em $10 \%$ o peso do critério de maior importância, Impacto no resultado, e realizado o ajuste dos pesos para os demais critérios. $\mathrm{Na}$ segunda foi reduzido em 5\% o mesmo critério. Na Tabela 3 os pesos da análise de sensibilidade são apresentados.

É importante destacar que durante a análise de sensibilidade com o acréscimo de $10 \%$ no peso do critério Impacto nos resultados, o somatório do fluxo líquido dos projetos selecionados teve um acréscimo de 2,2\% em relação ao modelo original, já que houve a variação dos fluxos líquidos de cada projeto, propiciado pela mudança dos pesos dos critérios. Nessa simulação não houve a alteração dos projetos selecionados, mantendo-se os mesmos da simulação original.

Quando foi realizada a simulação reduzindo em 5\% o peso do critério Impacto nos resultados, o somatório do fluxo líquido foi reduzido em 1,1\% e apenas o projeto AM16 deixou de integrar a lista de projetos selecionados. Com isso, a quantidade de projetos passou de 36 para 35, sendo que não houve alteração nos demais projetos. 0 fato de o projeto AM16 não ter integrado mais a lista de projetos se deveu ao seu fluxo líquido ter passado de positivo para negativo, sendo cortado durante o processo de otimização.

Pode-se destacar a robustez do modelo, já que mesmo com a alteração dos pesos dos critérios os projetos selecionados para o portfólio permaneceram praticamente os mesmos da aplicação original do modelo.

\section{Conclusões}

A relevância do tema gerenciamento de portfólio vem ganhando enfoque à medida que as organizações passam a adotar um modelo de planejamento estratégico de médio e longo prazos para alavancar sua vantagem competitiva.

Nos dias atuais, não basta que os projetos de uma organização sejam executados de acordo com o seu planejamento de custo e prazo. As organizações devem selecionar os melhores projetos para alavancar 
seus objetivos estratégicos, trazendo perenidade para o negócio.

Esse alinhamento entre estratégia e projetos é de fundamental importância, sendo que a aplicação de modelos que utilizam métodos multicritério de apoio à decisão são ferramentas poderosas para apoiar o tomador de decisão na solução tanto da problemática de seleção de projeto, quanto na problemática de seleção de portfólios.

Pode ser salientado que este artigo trata de um problema real em uma empresa de energia elétrica, com isso, possibilita identificar, no seu decorrer, vários pontos relevantes pertinentes ao estabelecimento de critérios e questões relativas à modelagem do problema multicritério.

Vale ser ressaltado que para atender ao objetivo de selecionar o conjunto de projetos que mais se enquadre na estratégia da organização, diversos critérios foram utilizados, desde critérios de caráter subjetivo até critérios puramente quantitativos.

Perante o cenário apresentado no decorrer deste trabalho, isto é, o ambiente no qual o grupo do setor elétrico está inserido e a janela de tempo na qual os projetos foram selecionados, o modelo construído obteve uma boa aceitação por parte do tomador de decisão, pois:

- Foi de fácil entendimento, levando em consideração o nível de detalhamento dos projetos no momento da seleção, possibilitando a utilização das informações disponíveis no momento;

- Apresentou a possibilidade de aplicação imediata do modelo desenvolvido, sem a necessidade de adequação dos processos internos;

- Atendeu aos requisitos e restrições impostas pelo tomador de decisão.

Vale ressaltar que, de forma similar à citada por Almeida (2011), a aplicação desse modelo foi facilitada pela base cultural e intelectual do decisor.

Os dois principais desafios enfrentados na aplicação do modelo foram descritos como:

- Necessidade de inúmeras interações com o decisor, principalmente no momento de julgamento dos projetos perante os critérios estabelecidos, sendo que esse fato tende a agravar-se caso se tenha uma quantidade inicial de projetos maior que a apresentada neste trabalho;

- Incerteza no julgamento dos projetos perante os critérios estabelecidos. Esse fato está diretamente ligado à quantidade de informações disponíveis no momento decisório.

A divisão dos projetos em categorias e a limitação do conjunto homem-hora/quantidade de projetos, possibilitou a seleção de um portfólio de projetos balanceado entre as principais diretrizes estratégicas, resultando com isso num alinhamento adequado entre estratégia e projetos. Esse fator possibilita também o uso mais efetivo dos recursos humanos, materiais e financeiros.

A aplicação do método PROMETHEE V, assim como o uso do suplemento Solver do Excel, atenderam às expectativas do trabalho, possibilitando facilmente processar os dados e disponibilizar os resultados do modelo.

Cabe ressaltar que os resultados obtidos foram relevantes e comprovaram, por meio da análise de sensibilidade aplicada, a robustez do modelo desenvolvido, possibilitando a ampliação da aplicação do modelo para a definição de outros portfólios dentro do grupo como, por exemplo, o portfólio de projetos de pesquisa e desenvolvimento (P\&D), sendo necessário para isso o devido ajuste nos critérios elencados.

Como conclusão, tem-se que o modelo desenvolvido atingiu os objetivos estabelecidos, possibilitando organizar, de forma estruturada e transparente, a problemática de seleção de projetos estratégicos do grupo.

\section{Referências}

AlMEIDA, A. T. O Conhecimento e o Uso de Métodos Multicritério de Apoio a Decisão. 2. ed. Recife: Editora Universitária, 2011.

ALMEIDA, A. T.; COSTA, A. P. C. S. Aplicações com métodos multicritério de apoio a decisão. Recife: Editora Universitária, 2003.

ALMEIDA, A. T.; DUARTE, M. D. O. A multi-criteria decision model for selecting project portfolio with consideration being given to a new concept for synergies. Pesquisa Operacional, v. 31, p. 301-318, 2011. http://dx.doi. org/10.1590/S0101-74382011000200006

ALMEIDA, A.T.;VETSCHERA, R.A note on scale transformations in the PROMETHEE V method. European Journal of Operational Research, v. 219, p. 198-200, 2012. http:// dx.doi.org/10.1016/j.ejor.2011.12.034

ARAGONÉS-BELTRÁN, P.; CHAPARRO-GONZÁlEZ, J. P.; RODRIGUÉZ-P0ZO, F. An ANP-based Approach for the Selection of Photovoltaic Solar Power Plant Investment Projects. Renewable and Sustainable Energy Reviews, v. 14, p. 249-264, 2010. http://dx.doi.org/10.1016/j. rser.2009.07.012

ARCHER, N. P.; GHASEMZADEH, F. An Integrated Framework for Project Portfolio Selection. International Journal of Project Management, v. 17, n. 4, p. 207-216, 1999. http://dx.doi.org/10.1016/S0263-7863(98)00032-5

ARTTO, K. et al. What is project strategy? International Journal of Project Management, v. 26, p. 4-12, 2008. http://dx.doi.org/10.1016/j.ijproman.2007.07.006

BARROS, L. A.; SILVA, C. E. S.; MEllO, C. H. P. Identificação de Fatores para Implementação de Técnicas de Gestão de Portfólio de Projetos: Um estudo de Caso em Uma Empresa Global do Setor Químico. Revista Produção, v. 10, n. 2, 2010.

BRANS, J. P.; MARESCHAL, B. PROMETHEE V: MCDM problems with segmentation constraints. INFOR, v. 30, n. 2, p. 85-96, 1992.

BUCHANAN J.; SHEPPARD, P. Ranking Projects Using the ELECTRE Method. In: ANNUAL OPERATIONAL RESEARCH 
SOCIETY OF NEW ZEALAND CONFERENCE, 33., 1998, New Zealand. Proceedings... New Zealand, 1998.

CASTRO, H. G.; CARVALHO, M. M. Gerenciamento de Portfólio de Projetos (PPM): Estudos de Caso. Produção, v. 20, n. 3, p. 303-321, 2010. http://dx.doi.org/10.1590/ S0103-65132010005000044

CHENG, E. W. L.; Ll, H. Analytic Network Applied to Project Selection. Journal of Construction Engineering and Management, v. 131-4, p. 459-466, 2005. http://dx.doi. org/10.1061/(ASCE)0733-9364(2005)131:4(459)

COOPER, G. R.; EDGETT, S. J.; KLEINSCHMIDT, E. J. New Problems, New Solutions: Making Portfolio Management More Effective. Research Technology Management, v. $43,2000$.

GOMES, L. F. A. M.; ARAYA, M. C. G.; CARIGNANO, C. Tomada de decisões em cenários complexos: introdução aos métodos discretos do apoio multicritério à decisão. São Paulo: Pioneira Thomson Learning, 2004.

GOMES, L. F. A. M.; GOMES, C. F. S. Tomada de decisão gerencial: enfoque multicritério. 4. ed. Rio de Janeiro: Editora Atlas, 2012.

GREINER, M. A. et al. A Hybrid Approach Using the Analytic Hierarchy Process and Integer Programming to Screen Weapon Systems Projects. IEEE Transactions on Engineering Management, v. 50-2, p. 192-203, 2003. http://dx.doi.org/10.1109/TEM.2003.810827

HAURANT, P.; OBERTI, P.; MUSELLI, M. Multicriteria selection aiding related to photovoltaic plants on farming fields on Corsica island: A real case study using the ELECTRE outranking framework. Energy Policy, v. 39, p. 676-688, 2011. http://dx.doi.org/10.1016/j. enpol.2010.10.040

JABLONSKÝ, J. SANNA 2009 - MS Excel based add-in application for multicriteria decision aid. Disponivel em: <http://nb.vse.cz/ jablon/>. Acesso em: 10 jun. 2010.

KENDALL, G. 1.; ROLLINS, S. C. Advanced project portfolio management and the PMO: multiplying ROI at warp speed. J. Ross Publishing, 2003.

KERZNER, H. Gestão de Projetos - As Melhores Práticas. 2. ed. São Paulo: Editora Bookman, 2005.

LEE, J. W.; KIM, S. H. An Integrated Approach for Interdependent Information System Project Selection. International Journal of Project Management, v. 19, p. 111-118, 2001. http://dx.doi.org/10.1016/S02637863(99)00053-8

MAVROTAS, G.;DIAKOULAKI, D.; CAPROSP. Combined MCDAIP Approach for Project Selection in the Electricity Market.
Annals of Operations Research, v. 120, p. 159-170, 2003. http://dx.doi.org/10.1023/A:1023382514182

MAVROTAS, G.; DIAKOULAKI, D.; CALOGHIROU, Y. Project prioritization under policy restrictions: a combination of MCDA with 0-1 programming. European Journal of Operational Research, v. 171, n. 1, p. 296-308, 2006. http://dx.doi.org/10.1016/j.ejor.2004.07.069

MEADE, L. M.; PRESLEY, A. RetD Project Selection Using the Analytic Network Process. IEEE Transactions on Engineering Management, v. 49-1, p. 59-66, 2002.

MESKENDAHL, S. The Influence of Business Strategy on Project Portfolio Management and its Success - A Conceptual Framework. International Journal of Project Management, v. 28, p. 807-817, 2010. http://dx.doi. org/10.1016/j.jproman.2010.06.007

OPERADOR NACIONAL DO SISTEMA ELÉTRICO - ONS. $O$ Setor Elétrico. Disponível em: <http://www.ons.org. $\mathrm{br} /$ institucional/modelo_setorial.aspx>. Acesso em: 20 out. 2010

PROJECT MANAGEMENT INSTITUTE - PMI. A Guide to the Project Management Body of Knowledge (PMBOK). Project Management Institute PMl, 2008.

PROJECT MANAGEMENT INSTITUTE - PMI. The Standard for Portfolio Management. Project Management Institute PMl, 2006.

ROY, B. Multicriteria Methodology for decision Aiding. Netherlands: Kluwer Academic Publishers, 1996.

SCHETTINO, S.; CORDEIRO, A. A. Metodologia para Priorização de Investimentos com Restricões Regulatórias e Financeiras. In: CONFERÊNCIA BRASILEIRA SOBRE QUALIDADE DA ENERGIA ELÉTRICA, 13.; 2009, Florianópolis. Anais... Florianópolis, 2009.

SMITH-PERERA, A. et al. A Project Strategic Index proposal for portfolio selection in electrical company based on the Analytic Network Process. Renewable and Sustainable Energy Reviews, v. 14, p. 1569-1579, 2010. http:// dx.doi.org/10.1016/j.rser.2010.01.022

VETSCHERA, R.; ALMEIDA, A. T. A PROMETHEE-based approach to portfolio selection problems. Computers $\&$ Operations Research, v. 39, p. 1010-1020, 2012. http:// dx.doi.org/10.1016/j.cor.2011.06.019

\section{Agradecimentos}

Este trabalho teve o suporte parcial do CNPq.

\title{
Project portfolio selection in an electric utility company using PROMETHEE V
}

\begin{abstract}
This study aims to develop a model for project selection based on the strategic planning of an electric utility in Brazil, which will compose the annual project portfolio. The selection of these projects is made in the absence of information with sufficient detail for the use of the most commonly applied quantitative criteria, for example, the internal rate of return and the net present value. To develop this model, we used the decision support method PROMETHEE $\mathrm{V}$, which allowed for the incorporation of existing restrictions on the model, using integer linear programming. The model is shown to be extremely robust and achieved the study aims.
\end{abstract}

\section{Keywords}

Project selection. Multicriteria decision analysis. PROMETHEE. 